\title{
Editorial
}

\section{The open clinical and the group analyst: their transferences and the common}

Tales Ab'Saber

Context

Since 2014, in Brazil, a large movement of taking over public spaces by free, collective, and social work by psychoanalysts has taken place. This movement of socialization of psychoanalysis and clinical and theoretical discussion of its commodified bases preceded the radical turn to the right of the country's political life, which partially criminalized the institutional left, Lula's labor party, and brought to power a hybrid government of neoliberalism and neofascism, very Brazilian. In any way you look at it, a movement radically opposed to all social life that performs collective, common, free-access, universal work. The public psychoanalytic clinics, however, continued their work with full vitality. Their strength came from their theoretical roots

*1,2 Universidade de São Paulo - USP (São Paulo, SP, Brasil) . 
and their social truth. The Open Psychoanalysis Clinic (Clínica Aberta de Psicanálise), at Casa do Povo in São Paulo, was one of the forerunners of this movement, which nowadays has become a national movement, in spiritual confrontation with the national conversion to selfishness and the most radical social abandonment, very typical of the new right-wing in Brazil.

Psychoanalysis was profoundly marked by the structuring, ideologically real fantasy of the individual's psycho-social reality, his existence, and his problems. Freud's discipline was originally constituted in the field of the effects of the modern individual's life's, as the idea of the psychology of the heroic figure of the individual - and the scientific hero doctor, like so many other heroes, in the culture of the symbolic market of individuals - an existing and integrated psychological being under the plural intensities of the multiple spheres of the existence in modernity. As an ideological conception that also composes it, the multiplicity of the modern practice's own life was bundled together and referred to the figurative idea of each one's monadic responsibility, a cultural ideological superego of narcissistic effects. Thus, the field of the individual subject's adventure was configured. This "free man" in the open market of possible outcomes of the constant expansion of the Capital over lives, with his social and intimate journey and his formation via the entire modern world. Some subjective ideological figures are known amidst the historical process of said psychology, and practical ideology, which was becoming widespread: the protestant puritan and his radical personal ethical loneliness before God and the bible; the Faustian bourgeois hero who alone creates the industrial world and designs the new Society; the image of the isolated social Robinson Crusoes, so criticized by Marx, as the pragmatic master of science and technique; or even the brilliant romantic artist, or his philosopher, who, always alone, constructed or deconstructed all the meaning of their world.

We can clearly observe this titanic figure of modern subjectivation in all 19th-century novel literature. We can also see its fraying, actually a symbolic and emotional fraying of itself, with psychoanalysis and the historical limitation of the world's infinite expansion of progress illusions — with its order of general destruction that presented itself wholly in the 20th-century. This really flawed and incomplete dimension of the modern individual, of his historical purpose and his Enlightenment's metaphysics, loses value to itself at the height of its process of historical configuration. This dimension was very present in the modern advanced literature, from Flaubert to Dostoevsky, Machado de Assis, and Henry James, to Kafka or Becket. In fact, the modern 
individual's cutting-edge novel literature configurated and anticipated in everything, and in details, the world of theory and the need for psychoanalytic work under a self that could no longer resolve itself within its own limits. This is because artists and poets knew straight away what men of science needed to access through their hard work, said Freud. That rational and autonomous modern individual, a presupposed theoretical-ideological entity with subjectivizing effects, was, with its development, questioned in its roots and psycho-political structures, by the literature of its time, by the science of the enigma of the unconscious of psychoanalysis, as well as by a significant part of contemporary philosophy. At best, the individual became a conceptual and political figure, partial and alienated in his own way, to the multiple forces and many others that compose him as we have come to understand.

We live in a contemporary crisis of the reproduction of life about the order of late modernity, of the turbocharged and total capitalism of today's world — degrading of life on earth, permanently questioning the space of public political organization and producing the spectacle of the unique validity of the image and the commodity in the human world, its only subject. In the collective work presented here, under this crisis, the device and the 514 effects of the group's existence, articulated in the psychoanalytic model, appear to us as an entity and a potency for life, as true and productive as once was the traditional modern individual, hero of the novel pages of his time. This displacement we propose, in the image and composition of the individual that articulates psychoanalysis in the world, implies political shifts and of the unconscious fantasies of all kinds. Those revive our understanding of clinical work together with its ever-present politics in the world, hidden or revealed, and its virtualities and potencies in a critical world. A joke can give us a some condensed news on these modulations of life and creation, specific to groups: psychoanalyst Marília Velano once said about the workgroups of psychoanalysts that the analysts, collectively, form schools... but they can never form ... a rock band! What are the limitations of this collective work and what do they imply? The Open Psychoanalysis Clinic and the Analyst Group (Grupo Analista), formulated by me and by a group of colleagues in São Paulo, Brazil, is the concrete answer to this question.

Below, we present some statements and specific emotional positions expressed by patients - or users, or citizens... - during the analytical work of the Open Psychoanalysis Clinic at Casa do Povo, a cultural center of universal access, in a central neighborhood of São Paulo that combines Brazil's poor and middle class. These statements reveal the complex and 


\section{EDITORIAL}

sensitively rich modality of transference, or transferences, on many levels vertical, group, collective, personal, institutional, or with the device itself, the collective setting - produced and recognized by the work carried out in this widely accessible clinic by the analyst or group therapist, or group analyst, as we have come to call it. The names cited by the patients refer to some of the analysts that take turns seeing them, but it is understood that, since the shift and expansion towards the current model of group psychoanalysis specific to this setting, each patient is a patient of the whole group instead of being attended to by a single analyst:

"... Marilia told me something the other time that got me thinking that I was like a plane that flew always on the same lane, that never left the same mode and space, even though it could..."

"Annie, what a woman..., the conversation with her was very important for me..."

"I met Tales the last time and he was wearing a soccer $t$-shirt... today when I was coming here, I remembered this... and I had put on a soccer $t$-shirt, and if that's not transference, I don't know what is..."

"in the beginning, I was thinking... does this really work, talking to a different person each time? I thought I would have to say everything all over again each time I talked to a different analyst... now that I have come here so many times, I see that's not the case... I say whatever I want and what I'm thinking each time, and I don't have to repeat myself... it is because you work together that you all know about us, isn't it?"

"I keep thinking, you are different, each and every one, Miranda is Miranda, Ricardo is Ricardo, Fabricio is Fabricio, each person has their own way... each one speaks differently... but you are also very similar... very similar... why is that?"

"I keep thinking, I thought it would be hard to talk to different people each session. But that is not the case. Every time I come here, I think, who am I going to talk to today? I do not know. And I think that's good, interesting. Today I think the opposite of what I thought in the beginning. Each one tells me something different, sees me differently, has a different way of speaking. And that is good. I keep thinking that, if I always talked with the same person, always with Ricardo or with you, maybe I would repeat myself, maybe I would be stuck on the same things, only with that person... this way I don't repeat myself..., and that's good. 
“... I'm only telling you about this dream again so that the analysts have continuity in their work..."

"I am coming here because I was told that this is a place for a new start in life..."

In each of these sentences collected from the clinic, psychoanalysis updates itself and reveals its differential productivity, revised by the theoretical/real shift of the original setting performed in this work. These are but a few of the transferential effects of the setting of the public clinic and social psychoanalysis movement, in life in the city, of the Open Psychoanalysis Clinic: a work in which psychoanalysts take turns weekly in a clinical shift, consider the patients as patients of the analytic group of analysts and not individual patients of individual analysts, and develop a collective work of elaboration and analytical "dreamery" about the patients, and the group of patients, the group patient. We are in the sphere of polyphony of the dream, the articulation of the multiple creations by the individual unconscious with the work of the unconscious of a group (Kaës, 2002). All stages of the work are carried out according to and through the fundamental Freudian method: free 516 association of patients joined with free-floating attention, with the suspension of desire and memory on the part of the analysts. And also, the group of psychoanalysts' elaborative associative work about the patients, in a place and time suited for this. These structures of group and social commitment are entirely permeated, at all times, by the psychoanalytic method first. That thread that unifies and makes work all the stages of the idea of social clinic achieved here, thus, articulating it to the fundamental model of the Freudian unconscious and testing it in this new way. That is why it is about psychoanalysis and not about another modality of clinical reception. In multiplying individuals for the group's and the cultural and social setting's potencies, it is psychoanalysis itself, in its fundamental principle, that is multiplied. It is a clinic that, as we will see, comes from the tradition of the psychoanalytic field, is inscribed in it, and reads its results by its criteria and parameters.

The first point to be noted of a new human structure of encounter and experience, a psychoanalytic setting, operating on the Freudian method's regime and its model of the unconscious as a background, is that it can give us real and concrete fresh news about the unconscious and its potencies of meaning (Anzieu, 2000). Let us look at a well-known historical example. The analyst and pediatrician Donald Winnicott only came to recognize and think about the new psychoanalytic logic of the transitional objects and phenomena 
after twenty-five years of work in a renewed setting of his psychoanalysis, present in the public clinic in an English pediatric hospital (Winnicott, 1936/1988, 1941). His public psychoanalytic action was not coincident with his own personal and individual setting, and this shift not only extended the power of the social presence of psychoanalysis in the world but also prompted the production of clinical problems that hadn't yet been perceived or thought of. The setting, the sensorial nature of the care relationship, its chosen form of space, time and presence, its place in the symbolic and cultural life of the city and the human and political configuration of the analyst, or the analysts, that he proposes, was always the true source and the final destination of psychoanalysis' theoretic life. Psychoanalysis stems from its live experience, its symbolic thing that is an event, to then be thought of. And, secondly, as a theory, psychoanalysis also returns to the setting. In the origin, before any properly psychoanalytical theoretical data, psychoanalysis was initially a clinical human experience of setting, the original clinical space, invented by Josef Breuer, before Freud, where the fundamental experiences were born, under the statute of observation and the presence of the analyst, which then allowed Freud's genius, the radical, theoretical and clinical development of his knowledge (Breuer, \& Freud, 1895/2017).

The Open Psychoanalysis Clinic is a psychoanalytical setting. A setting which, in its way of presenting itself, its political form of organization and practice propositions, its biopolitical device character, as Foucault would say, articulates social and theoretical elements of the psychoanalytic discipline in a new way. This way of thinking and organizing psychoanalysis in the world is only possible today, after 120 years of continued and accumulated historical psychoanalytical experience because it counts integrally with the presence of history in its constitution. It is a contemporary articulation in the depth of the theoretical possibilities of this history, its multiple observations, and constructions of the psychoanalytical experience. This setting organizes, makes organic, the following heterogeneous elements, unified now by a common desire: public space, group subject of the analysts at work, mutual creation of the workspace with the patients, clinical on-call of free and universal access, absence of bureaucratic overload or social control mediated by money, attentive listening to the communication potentials of the single session, rotation of the analysts in the continued care of patients that wish to proceed with the work and the therapeutic project drawn by the patient, in one or multiple sessions, with a non-pedagogical nor adaptative understanding of what is analysis. This configuration responds precisely to the potential of a 
multiple displacement, the plurivocity of the Freudian unconscious, in his own words about dream formation, and to the statute of the unconscious group functioning, as observed by Rene Käes and his workgroup in Lyon.

The historical existence of the potential moments of intense feelings in the single session, already researched with children since the pediatric psychoanalytical work of Donald Winnicott from 1930 to 1970 (Winnicott, 1941/1971); the discipline of the emotional attention to the here and now, central understanding to the Kleinian tradition, which unfolds itself and complements the psychoanalytical method of free-floating attention, and of free association with the work of memory and desire suspension - in an excessive de-reference to the past and the future on behalf of the analyst (Bion, 1967/1990); and the group of unconscious elaboration of the analysts about the patients, as well about the group of (Käes, 2006), are the classic elements of the history of psychoanalysis that were joined and synthetized in the form of production of experience with the Freudian unconscious that we call Open Clinic and Analyst Group.

Thus, the clinic, as a contemporary structure of intervention, is in fact a Reading of the history of psychoanalysis. In addition, from another 518 perspective, the radicalization of the social-political link of the analytical practices and its production of socially oriented symbolic systems are also at stake, to conceive the reproduction of the symbolic reality of the liberal market as a contingency and not as a real structure of psychoanalysis. The clinic is a political, psychoanalytic act of radically common interest, where new practices of existence and de-alienation of the idea and place of work, for patients and analysts, must occur. Group, collective and social psychoanalysis, at the root of the possibility of universal access as a wish and therefore without the socially unequal, politically controlled regulation of money (Brown, 2016). New practices of circulation and occupation, of life, in the city are part of the new clinical work. The value of work and the distribution of values is emphasized through the democratizing socializing apex, the desire for free work, and not through the interested and reproductive mediation of the order of regulated exclusions by the market form, the general mediation of accumulation. From this point of view, the perspective of the work at The Open Clinic articulates psychoanalysis and some virtuality of post-capitalist life. The Clinic operates simultaneously as care and as politics, as work by transformation and work by the critics. And the patients know that. They share this political desire from the work with the unconscious with the analysts. Everyone works for themselves and an undetermined beyond. 
We can then observe the patients' production on this offer and themselves. Multiple times, commitments and rhythms of analysis; suspension of the teleological character of the analytical experience; dismantling of their territorialized social commitments; imagined community of patients who share the care of The Open Clinic with the analysts themselves; expressed gratitude and political gratitude; transference love with the psychoanalysts' group and with the public space that receives the work and the collective, plural and democratizing subjectivizing effects. These meanings are expressed in the short sentences collected above.

Besides providing an experience of the unconscious, which is at its core, The Open Clinic is an experience of subjectivation, of open political effects, supported by psychoanalysis in all points. The patients' interest in their organization and the analysts' investment in their analyst group reveals a work of psychic background, of dialectic character, in which the thought to and about the other's form - here a social form made of knowledge and desire, the group analyst - grounds, through strata of the thought its self's movement, a background identification, fundamentally political. The patients 'work on the meaning of that experience, new to them, still inaugural in their lives and the city's social life, also leads to the establishment of the self from the experience with another, in a work that is strongly inscribed as an itself. Patients feel coauthors of the psychoanalysis that receives them, and of the political device they have elected, through transference at work. Moreover, this is a self-creative dimension of psychoanalysis, method, and setting that - ever since the original observations by Bertha Pappenheim about her needs of psychic movement to her analyst doctor Josef Breuer, who listened to them, in the first historical experience of psychoanalysis - should never have been abandoned by psychoanalytic listening and technique (Ab'Sáber, 2016).

Another important point is the idea of celebration and gratitude that goes across all this setting and work. The moment of a group narcissism that erotically detaches the collective from the rest of humanity is well known and is part of the movements set up by group psychoanalysis. However, there is a surplus of eroticism in this process that we can call truthful and structural: the existence of an object of civilization, a personal analysis, free from the mechanisms of control and access, of restriction and embarrassment, characteristic of the norms, barred from thought, of the sale of services in the liberal labor market. Free from psychoanalysis organized as merchandise (Le Flore, R., 2016). In classical terms of psychoanalytic economic thought, we can say that the energy and the control unspent with the harsh liberal contract 
of the service market, which connects psychic possibilities in a predetermined way, in a real ideological blind spot of the method, are forces which become free in the public modality of setting. By dismissing work from the liberal economic contract, the space of experience is freed up for investment in the analytical work itself, and also for the erotic and symbolic overflow of the real encounter with a good object, which by franchisee, becomes created by the patient himself. Ethically, we are talking about a gesture of loving offering and human interest that efficiently surpasses commodity's reason and the underlying logic of the encounter of the market, which is a field for an encounter, research, and celebration, political spaces of meaning production.

The clinic that is organized to be offered as the new gift economy, by the political and erotic desire of its workers, potentiates the fundamental transitional aspect that exists in all psychoanalysis and all human development: it is an object dreamed of experience, which is there to be lived, in the city made common. Patients find that which they feel they also create, more radically than in other social settings. Hence the eroticism, the civilizing joy, the effect of gratitude, a type of loving bond, unknown in other analytical circuits, which is created by this way of giving an experience of the Freudian unconscious and the Winnicottian self to the world.

Finally, for now, we are left with the important indication for the unconscious theory and the transferential object relation at stake, counterintuitive: that which with the progression of the analytical work at The Open Clinic patients feel a reversal in their original imaginary system, linked to culture and not to experience, regarding what psychoanalysis is and its doings. As told by themselves, they may come to feel that encounters with multiple analysts in each session allow for more movement and more freedom than would occur if they were being heard by a single analyst. The loving kind bond and the guaranteed backing of a qualified work with the unconscious disband the ideology "of the psychoanalyst, his couch and his cost", reinaugurating the first potential of the clinic's open experience for the patient and psychoanalyst alike.

From this perspective, the resistance of psychic work and of the limits of its potential to create is referred to the traditional work form, inverting the known norm from the expansion of the device. Quite the opposite of what is assumed by psychoanalytic and cultural common sense. Psychoanalysis is an ethical theoretical experience of transformation, which puts into motion imagined settings for it to exist, and not something fixed to the historic form of a specific setting. In fact, in this intuition of their critique to 


\section{EDITORIAL}

psychoanalysis, patients seem to refer to the multiple intermediate knots, of the multiplication of the associative chains in the space of dream formation, which articulate, in their multiplicity, are always more than one, the work of connecting and disconnecting the displacement and the condensation of the psyche. As Didier Anzieu said one day, the group is like the dream.

Contrary to the fantasy of the solid integrity of the individual object as an originator of transference, the classic single non-transferable analyst, the existential chain of multiple listening analysts could work as something of the multiplicity of the psychic knots that organize and reorganize the network of a dream, from the Freudian understanding of what a dream is, increasing, in a social and collective principle, the capacity and the productivity of psychic mobility, essential to any nature of transformation.

\section{References}

Ab'Sáber, T. (2016). Self cultural, sujeito do inconsciente e história. Livro eletrônico, São Paulo: e-galaxia.

Anzieu, D. (2004). Tornar-se psicanalista hoje. In Psicanalisar. Aparecida, SP: Ideias e Letras. (Work originally published in 2000).

Bion, W. (1990). Notas sobre desejo e memória. In Melanie Klien hoje (Vol. 2). Rio de Janeiro, RJ: Imago. (Work originally published in 1967).

Brown, W. (2016). El pueblo sin atributos. Barcelona, ESP: Malpaso.

Breuer, J., \& Freud, S. (2017). Estudos sobre a histeria. In Sigmund Freud, obras completas (Vol. 2). São Paulo, SP: Companhia das Letras. (Work originally published in 1895).

Käes, R. (2006). A polifonia dos sonhos. Aparecida, SP: Ideias e Letras. (Work originally published in 2002).

Le Flore, R. (2016). The American gift economy. Livro eletrônico, Amazon.

Winnicott, D. (1988). Apetite e perturbação emocional. In Da pediatria à psicanálise, Rio de Janeiro, RJ: Francisco Alves. (Work originally published in 1936).

Winnicott, D. (1988). A observação de bebês em uma situação estabelecida. In $D a$ pediatria à psicanálise. Rio de Janeiro, RJ: Francisco Alves. (Work originally published in 1941).

Winnicott, D. (1984). Consultas terapêuticas em psiquiatria infantil. Rio de Janeiro, RJ: Imago.(Work originally published in 1971). 
Citação/Citation: Ab'Saber, T. (2021, dez.). Editorial. The open clinic and the group analyst: their transferences and the common. Revista Latinoamericana de Psicopatologia Fundamental, 24(4), 512-522. http://dx.doi.org/10.1590/1415-4714.2021v24n4p512.2

Editoras/Editors: Profa. Dr. Nelson da Silva Jr. e Maria Livia Tourinho Moretto

Recebido/Received: 24.11.2021 / 11.24.2021 Aceito/Accepted: 25.11.2021/ 11.25.2021

Copyright: (C) 2009 Associação Universitária de Pesquisa em Psicopatologia Fundamental/ University Association for Research in Fundamental Psychopathology. Este é um artigo de livre acesso, que permite uso irrestrito, distribuição e reprodução em qualquer meio, desde que o autor e a fonte sejam citados / This is an open-access article, which permits unrestricted use, distribution, and reproduction in any medium, provided the original authors and sources are credited.

\section{TALes AB'SÁBer}

Psicanalista; Membro do Departamento de Psicanálise do Instituto Sedes Sapientiae; Professor de Filosofia na Universidade Federal de São Paulo - Unifesp (São Paulo, SP, $\mathrm{Br}$ ). Autor, entre outros, de: O sonhar restaurado, formas do sonhar em Bion, Winnicott e Freud (Editora 34, 2005); A música do tempo infinito (Cosac Naify, 2012) e Michel Temer e o fascismo comum (Hedra, 2018).

Rua Joquim Antunes, 490/21

05415-001 São Paulo, SP

luamartevenus@gmail.com

https://orcid.org/0000-0003-1761-6111

(cc) BY-NC

This is an open-access article, which permits unrestricted use, distribution, and reproduction in any medium for non-commercial purposes provided the original authors and sources are credited. 